\title{
A Rare Interstitial Type of Post Appendectomy Incisional Hernia
}

\author{
Katari Gopalakrishnan Vishnukumar*, Sudharshan S. Murthy, Abishek Kandasamy \\ Rajasabapathy, Kulandaiyagounder Ramaswamy Manoj Prabu, Arcot Rekha
}

Saveetha Medical College, Chennai, India

Email: *vishnukgvk@gmail.com

How to cite this paper: Vishnukumar, K.G., Murthy, S.S., Rajasabapathy, A.K., Prabu, K.R.M. and Rekha, A. (2021) A Rare Interstitial Type of Post Appendectomy Incisional Hernia. Case Reports in Clinical Medicine, 10, 146-151.

https://doi.org/10.4236/crcm.2021.105018

Received: March 29, 2021

Accepted: May 23, 2021

Published: May 26, 2021

Copyright $\odot 2021$ by author(s) and Scientific Research Publishing Inc. This work is licensed under the Creative Commons Attribution International License (CC BY 4.0).

http://creativecommons.org/licenses/by/4.0/

\begin{abstract}
Intraparietal Hernias are hernias occurring in the anterior abdominal wall at different anatomical planes. An interparietal hernia has a hernial sac that passes between the layers of the anterior abdominal wall. Appendectomy is a very common surgical procedure, and post appendectomy incisional hernia is a very rare complication. Here we present a case of a 24-year-old male with swelling in the right hypochondrium and lumbar region with an open appendectomy scar. He was diagnosed to have an interparietal hernia in the anterior abdominal wall. After obtaining consent patient was taken up for surgery. At surgery, the patient was found to have a defect in the transverse abdominis muscle with a medial leaf far from the incision site. Open repair of the defect along with double breasting of external oblique done. Interparietal hernias are rare in post appendectomy scar and this case is of significance since it Highlights a rare interstitial type incisional hernia, as a complication of post appendectomy scar, and not many cases reports are mentioned in literature.
\end{abstract}

\section{Keywords}

Interparietal Hernia, Post Appendectomy Incisional Hernia, Interstitial Type, Abdominal Wall Defect, Double Breasting

\section{Introduction}

One of the rare hernias occurring at the anterior abdominal wall is the Interparietal hernia which occurs at various anatomical (parietal) planes. An interparietal hernia has a hernial sac that passes between the layers of the anterior abdominal wall. This sac may be associated with, or communicate with, the sac of a concomitant ventral hernia. These types of hernias are difficult to suspect clinically or to diagnose radiologically hence it is usually missed or diagnosed lately or most- 
ly as an intraoperative finding. In our case also, both USG could not diagnose it as an interparietal hernia, CT gave a picture of plane of the swelling, However, the extent of defect could not be accurately assessed which was finally seen intraoperatively and was treated accordingly by approximating transverse abdominis in upper $2 / 3^{\text {rd }}$ and lower $1 / 3^{\text {rd }}$ was sutured with internal oblique since the in lower part two leaf of transverse abdominis was far apart followed by double breasting of external oblique was done. This is a significant rare case interstitial type incisional hernia following post appendectomy as not many cases are found in the literature.

\section{Case Report}

A 24-year-old male came to Surgical Op with complaints of swelling in the Right hypochondrium, which was gradually increasing in size for the past 6 months. It increased with straining and reduced on lying down. Patient underwent open emergency appendectomy one year back. At physical examination of patient, a 5 $\times 5 \mathrm{~cm}$ swelling with an expansile cough impulse was noted in the region of appendectomy scar. His laboratory investigation showed hemoglobin $17.1 \mathrm{~g} / \mathrm{dl}$, hematocrit-51.6\%, leucocytes-12,900, platelets-249,000, Na-139 mg/dl, K-4.0 $\mathrm{mg} / \mathrm{dl}, \mathrm{Cl}-106 \mathrm{meq} / \mathrm{dl}$, CT abdomen-A defect seen in anterior abdominal wall along the right transverse abdominis muscle fibers of size $5 \times 4.2 \mathrm{~cm}(\mathrm{AP} \times \mathrm{TR})$ through which herniation of omentum and ileal loops is noted with resultant laxity and stretching of the right external oblique muscle fibers noted (Figure 1 and Figure 2). The patient was posted for open repair with the diagnosis of Incisional interparietal hernia. Incision was made over the previous scar site and scar tissue was excised; Incision was deepened. Thick fibrous scar tissue was seen. External oblique fascial plane made. Defect of size $6 \times 5 \mathrm{~cm}$ noted, hernial sac was adhered to external oblique muscle \& aponeurosis. Sac opened and the contents were found to be small bowel and omentum (Figure 3). Adhesions between bowel and sac released and contents reduced. Defect was seen in transverse abdominis muscle with medial leaf $4 \mathrm{~cm}$ from incision site. After releasing bowel adhesions, to the inner surface of external oblique the Transverse abdominis muscle defect was approximated with 1.0 prolene only in upper $2 / 3^{\text {rd }}$ of defect

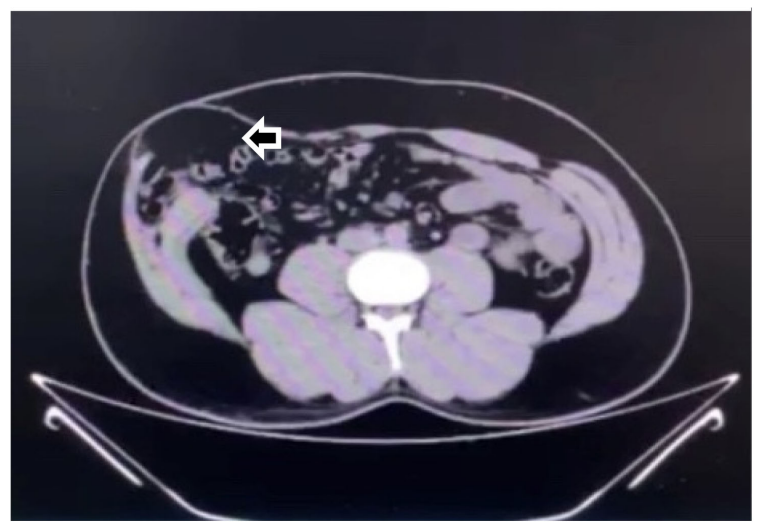

Figure 1. Pre-operative CT image arrow showing the interstitial incisional hernial sac. 


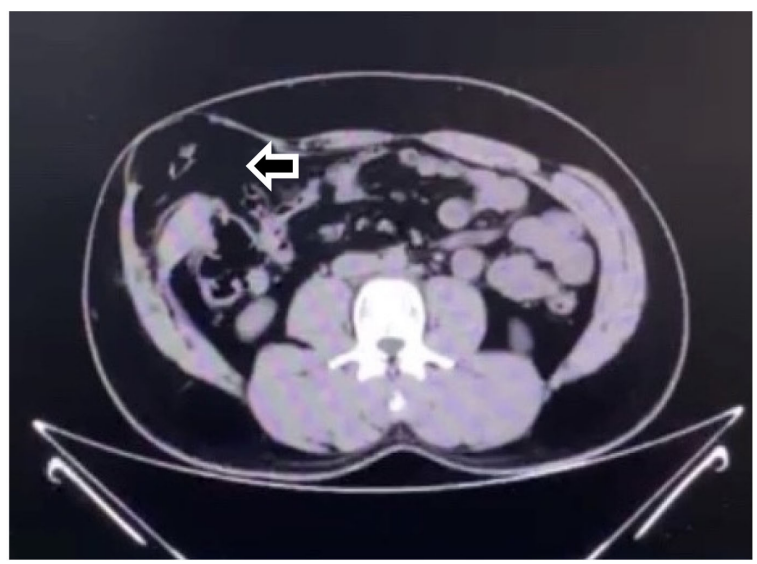

Figure 2. Defect of transverse abdominis Arrow showing bowel and omentum as content in hernial sac.

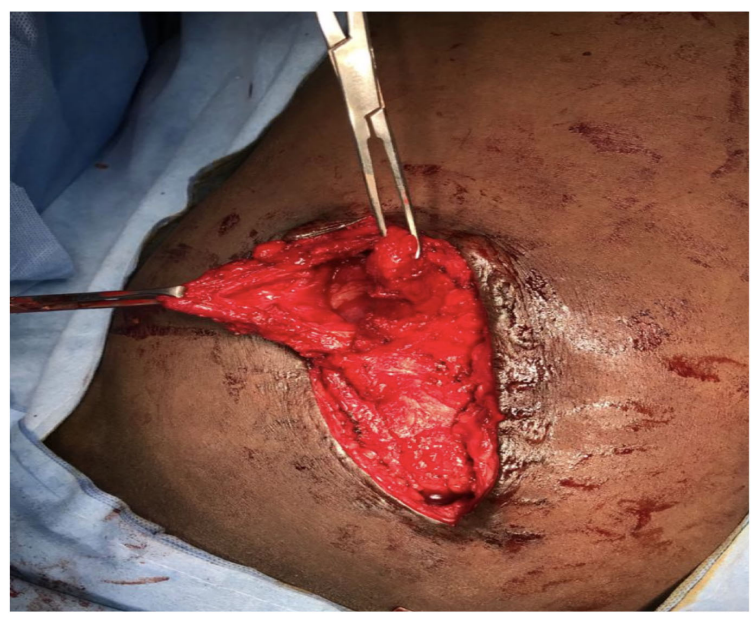

Figure 3. Defect with Internal oblique and transverse abdominis held.

(Figure 4). In lower $1 / 3^{\text {rd }}$ Transverse abdominis muscle lateral leaf is seen near Anterior superior iliac spine and medial leaf seen near pubic symphysis hence medial leaf of muscle is sutured with internal oblique muscle (Figure 5). Double breasting of external oblique done (Figure 6). Suction drain placed skin sutured. Patient was comfortable post-operatively and was discharged on $4^{\text {th }}$ post-operative day. He was free of any symptoms after his follow at 3 months.

\section{Discussion}

Bartolin was the pioneer to describe interparietal hernia in 1661 [1]. Interparietal hernia comprises nearly $0.01 \%-1.6 \%$ of all hernias. Lower abdomen interparietal hernias are usually confused with the inguinal hernia mostly determined only at the time of operation. Sometimes lower abdomen intraparietal hernias frequently present with small bowel obstruction. Sub-types of Interparietal hernias include preperitoneal (between the peritoneum and transversalis fascia), Interstitial (between the muscle layers of external oblique and internal oblique), Superficial (between the skin and external oblique muscle) [2]. 


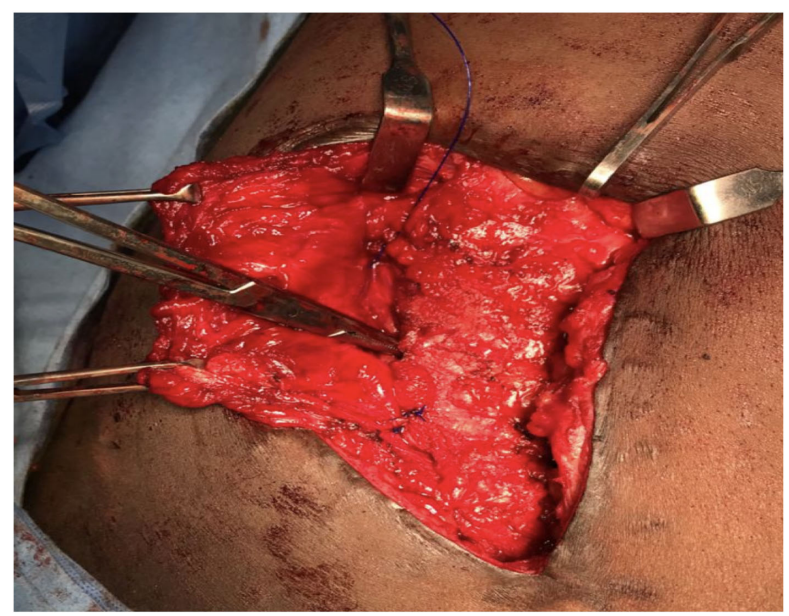

Figure 4. Upper half of transverse abdominis after suturing.

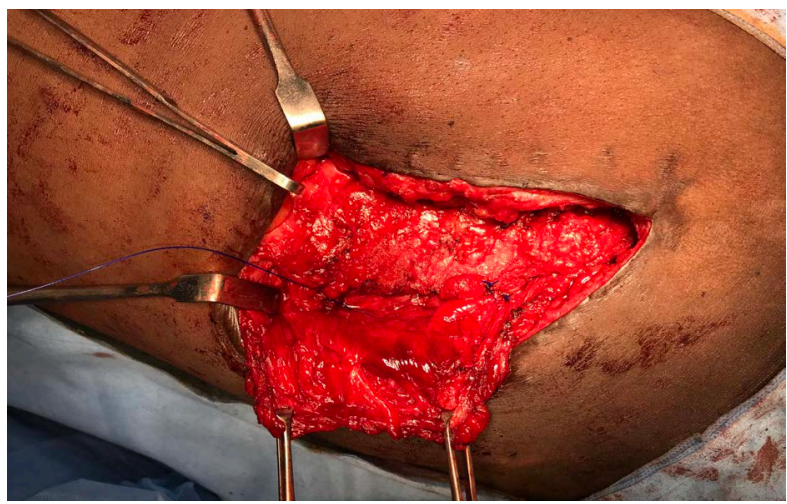

Figure 5. Lower half of transverse abdominis sutured with internal oblique.

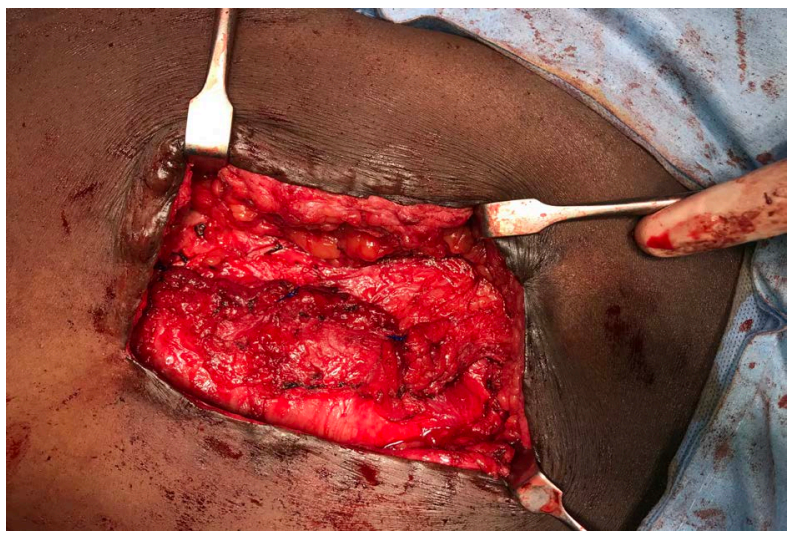

Figure 6. Double breasting of external oblique.

Prevalence of interstitial Sub-type is $60 \%$. While other two combined accounts for $29 \%$. Incidence of Interstitial hernia following abdominal surgeries is $10 \%$ [3].

These interparietal hernias predominantly occur in males and more common in children.

Interparietal hernia has a hernial sac which passes between layers of anterior abdominal wall. The sac may be associated with or communicating with sac of 
concomitant inguinal or femoral hernia. These types of hernia present with obstruction or strangulation, which is often missed or diagnosed late because swelling is often absent in preperitoneal variety.

Interparietal hernia can sometimes present as Intestinal Obstruction appearing as an odd inguinal hernia. So, it is essential for surgeons to have correct preoperative diagnosis and plan for emergency surgery [4]. After appendectomy incidence of hernia is usually due to infection of wound in advanced peritonitis associated with local purulent peritonitis. Other reasons are drain when fixed tightly through incision may cause fleshly internal oblique and transverse abdominis muscle leading to necrosis [5].

Repair of the incisional Intrabdominal hernia is mostly done by anatomical repair. When tissue is atrophic, a thin overlap kind of repair is done and sometimes sutured with underlying structure along with strengthening of above layer by double breasting techniques [6]. Sometimes these defects are best treated with a sheet of polypropylene mesh, with a margin measuring at least 6-8 $\mathrm{cm}$ beyond the periphery of the defect, placed between the peritoneum and transverses abdominis muscle. Both techniques can be successfully implemented if the correct indications based on the extent of the defect and the clinical characteristics of the patient are respected [7]. Interparietal hernias are a significant complication resulting after any abdominal surgical incision. Significantly large defects of this variety can be successfully managed entirely with laparoscopic technique using barbed suture for primary repair of defect with subsequent mesh reinforcement [8]. In our case patient underwent open primary defect closure with double breasting of the external oblique muscle.

\section{Conclusion}

The combination of Incisional in post appendicectomy scar site is a very rare event. Even though the clinical diagnosis is challenging the treatment is surgical repair. Mostly diagnosed intraoperatively and not many cases find mention in a review of the literature. Hence great caution needs to be excised in the management of the patient with such kind of presentation.

\section{Conflicts of Interest}

The authors declare no conflicts of interest regarding the publication of this paper.

\section{References}

[1] Reddy, K.M., Stellakis, M.L.C., Khaliq, T. and Fiennes, A.G.T.W. (1999) Interparietal Hernia Mimicking Malignant Small Bowel Obstruction. Hernia, 3, 37-38. https://doi.org/10.1007/BF01576741

[2] Zollinger, R.M. (2002) Claasification of Ventral and Groin Hernias. In: Greenburg, A.G. and Fitzgibbons, R.J., Eds., Nyhus \& Condon's Hernia Lippincott, Williams \& Wilkins, Philadelphia, 71-79.

[3] Popovic, J.R. and Hall, M.J. (2001) 1999 National Hospital Discharge Survey. Ad- 
vance Data, 3, 1-20.

[4] Gungor, B., Topgul, K., Bilgin, M. and Malazgirt, Z. (2010). Interparietal Herniation: A Rare Cause of Intestinal Obstruction. Journal of Medical Cases, 1, 58-60. https://doi.org/10.4021/jmc38w

[5] Abou-Nukta, F., Bakhos, C. and Arroyo, K. (2006) Effects of Delaying Appendectomy for Acute Appendicitis for 12 to 24 Hours. Archives of Surgery, 141, 504-506. https://doi.org/10.1001/archsurg.141.5.504

[6] Kumar, A., Saidha, N., Ramakrishnan, T.S. and Sahu, S. (2009). Interstitial Incisional Hernia Following Appendectomy. Medical Journal Armed Forces India, 65, 176-177. https://doi.org/10.1016/S0377-1237(09)80139-1

[7] Duce, A.M., Lozano, O., Villeta, R., et al. (1998) Incisional Hernia Following Appendectomy. Surgical Experience. Hernia, 2, 169-171. https://doi.org/10.1007/BF01569140

[8] Kalmar, C.L. and Bower, C.E. (2019) Laparoscopic Repair of Interparietal Abdominal Wall Hernias. Journal of Surgical Case Reports, 2019, Artile ID: rjz319.

https://doi.org/10.1093/jscr/rjz319 